\title{
Improvements in biomass production: Learning lessons from the bioenergy plants maize and sorghum
}

\begin{abstract}
Paper received: 07.04.2018
Revised received: 22.10 .2018

Re-revised received: 05.11 .2018

Accepted: 29.11 .2018

C.C. Ogbaga ${ }^{1}$, A.K. Bajhaiya ${ }^{2}$

\section{Abstract}

The use of biomass energy is preferred over fossil fuels as the former is more sustainable and emits a reduced amount of greenhouse gases. Sorghum, a tropical $\mathrm{C}_{4}$ plant, is known to have a marked drought tolerance. However, very little is known about the mechanisms involved. An allied species Zea mays, also a $\mathrm{C}_{4}$ plant, is far less drought tolerant. Both plants are known to accumulate high biomass during the course of their growth cycle and can be used as renewable energy sources. This article discusses the possibilities of using these two plants for the production of improved biomass in the context of drought tolerance and sustainable food production. Crucial and novel approaches that render Sorghum more tolerant to drought have been reviewed. Novel drought tolerance mechanisms in two sorghum cultivars- Samsorg 17 (more drought tolerant) and Samsorg 40 (less drought tolerant) have also been reviewed.
\end{abstract}

\section{Authors Info \\ and S.K. Gupta ${ }^{3 *}$ \\ 'Department of Biological Sciences, Nile University of Nigeria, Abuja, 900001, Nigeria \\ ${ }^{2}$ Department of Plant Physiology, Umeå Plant Science Centre, Umeå University, Umeå, 90187 , Sweden \\ ${ }^{3}$ Department of Civil Engineering, Indian Institute of Technology Delhi-110 016, India}

${ }^{*}$ Corresponding Author Email : sanjuenv@gmail.com

\section{Edited by \\ Dr. M. Ramya}

\section{Reviewed by}

Prof. Mohammad lqbal

Dr. Ramesh Kumar
Key words: Biomass energy, Drought stress, Maize, Sorghum

\section{Introduction}

Drought causes massive economic and agricultural losses and is forecasted to be exacerbated in the future due to global climate change (Chen et al., 2012; IPCC, 2013; Ogbaga, 2018). Drought in arid regions is further compounded by competition for land between the industrial and agricultural sectors. Since arable land available for agricultural use has decreased, there is a need to breed crops that can produce maximum yield on limited land. In the tropics, efforts have long been in progress to produce water-use efficient crops that can thrive in marginal lands. Attempts have also been made to understand the drought tolerance mechanisms operative in widely cultivated staple drought-tolerant crops such as Sorghum so as to aid in the improvement of other crops (Turyagyenda et al., 2013; Ogbaga et al., 2017b; Zafar et al., 2017). Breeding of less tolerant staple crops is essential to enable them survive with limited water resources.

Drought causes numerous morphological, physiological and biochemical changes in plants. Morphological effects are visible in the form of wilting of shoots and leaves of green plants. Adjustments in rooting, water uptake, and xylem structure can occur to offer some degree of drought tolerance (Ghannoum, 2009; Ogbaga et al., 2016). With regard to physiology and biochemistry, photosynthesis is altered due to disruption of electron transport chain and BensonCalvin cycle (Flexas and Medrano, 2002). Drought induces a variety of specific physiological responses in plants such as stomatal reaction ranging from partial reduction in stomatal aperture (leading to a decrease in photosynthesis) to complete stomatal closure (Blum, 1988; Blum, 2011). Stomatal closure is regarded as the earliest primary response of plants to stress, the secondary

How to cite : Ogbaga, C.C., A.K. Bajhaiya and S.K. Gupta: Improvements in biomass production: Learning lessons from the bioenergy plants maize and sorghum. J. Environ. Biol., 40, 400-406 (2019). 
responses mostly biochemical manifest only during severe stress (Chaves et al., 2003). The absence of stomatal effects in $\mathrm{C}_{4}$ plants has been explained as being due to PEPC having a high affinity for $\mathrm{CO}_{2}$ and thus enables $\mathrm{CO}_{2}$ fixation for a longer period during drought (Ghannoum, 2009; Chaves et al., 2009; Carmo-Silva et al., 2012). Plants can keep stomata open using various mechanisms to acclimate or tolerate stressful conditions (Chaves et al., 2009; Yamori et al., 2014). During stress, photosynthesis may decline to correspond to the stomatal opening.

This occurs together with the down-regulation of photosystem II and activation of cyclic electron flow to prevent the production of reactive oxygen species and for net ATP production (Takabayashi et al., 2005; Zegada-Lizarazu and Monti, 2013). It is debatable whether such a loss in photosynthesis leads to less accumulation of biomass. In the absence of any form of regulation, water deficit alters the linear electron transport ultimately leading to specific photosystem damage (photoinhibition) or production of reactive oxygen species (Medrano et al., 2002; Asada, 2006). Plant biomass is a renewable energy source that emits a reduced amount of greenhouse gases, and hence is considered sustainable. The high biomass plants have energy stored in them in the form of chemical bonds which can be released biologically or chemically to generate fuel (McKendry, 2002a).

The study of $\mathrm{C}_{4}$ metabolism can improve our understanding of how $\mathrm{C}_{4}$ plants partition carbon into sugar reservoirs and increase their cell wall thickness (Lawrence and Walbot, 2007). Maize and Sorghum are known genetic $C_{4}$ models that are considered as the tropical biomass plants (Lawrence and Walbot, 2007; Paterson et al., 2009b). The genome sequences of both plants have been completed and provide a knowledge base for determining gene functions (Carpita et al., 2008; Pennisi, 2008; Paterson et al., 2009b). The complete sequence of both plants allows for rapid gene identification by nested association mapping (NAM) or analysis of quantitative trait loci (QTL) of the genes important for useful traits, such as plant anatomy, architecture, height, leaf area, density and biomass (Yu and Buckle, 2006; Yu et al., 2008). The advantages of using these plants for genetic studies start with their close evolutionary relationship with bioenergy perennial grasses and $\mathrm{C}_{4}$ photosynthesis system. In order to increase the drought tolerance of maize and other plants of the same biochemical subtype, it would be crucial to understand the mechanisms by which both plants tolerate drought and accumulate biomass simultaneously. This article examines the possibility of using maize and sorghum plants for biomass production with special emphasis on the crucial and novel traits identified in Sorghum.

Photosynthetic electron transport and biomass production: In Calvin cycle, $\mathrm{CO}_{2}$ fixation occurs and energy is stored as glucose or sucrose (Zhu et al., 2008). With adequate nutrients, oxygen, water, and plant respiration, these sugars convert to biomass production in plants. In plant physiology, biomass production is assessed by net assimilation. Net assimilation is weight increase per unit area per unit time (Poorter and Remkes, 1990). The reducing power and adenosine triphosphate (ATP) required to drive the reactions of the Calvin cycle is generated from photosynthetic electron transport (Miyake et al., 2004; Ogbaga et al., 2014). The electron transport chain (ETC) contains two reaction centers (photosystems): PS II and PSI and a cytochrome b6f complex (Ogbaga et al., 2018). These are linked by plastoquinone and plastocyanin. PS II and PSI are the first and second protein complexes of ETC and occur in the mesophyll and bundle sheath chloroplasts respectively. The two proteins are regulated during drought with PSII being more susceptible to damage. ETC is responsible for the movement of electrons from water to NADP with $\mathrm{H}+$ translocated from the chloroplast thylakoid membrane to thylakoid lumen in the process. This translocation can generate non-photochemical quenching (NPQ), a photoprotective mechanism, which protects plants from damage during stress (Miyake et al., 2004).

Maize as a biomass plant: Maize is considered a $\mathrm{C}_{4}$ biomass plant, which can produce ethanol. Annually, over 4 billion gallons of ethanol is generated from maize kernel in the United States (Sticklen, 2006). For this to happen, the starch content is converted to sugar and subsequently by yeast to ethanol through fermentation (McKendry, 2002b). There are two main processes involved in this conversion-thermo-chemical and biochemical (McKendry, 2002b). In the former, the conversion of biomass to energy proceeds though one of the following routes- combustion, pyrolysis, gasification, and liquefaction. In the latter, the options are digestion (i.e., the production of biogas) and fermentation (McKendry, 2002b). The choice of the route depends on the type of bioenergy sought. For instance, in the United States, fermentation seems to be the preferred option for ethanol production in industries. Few strategies that have been shown or suggested to improve either drought tolerance and/or biomass accumulation in maize include- Selection of improved cultivars, increase in atmospheric $\mathrm{CO}_{2}$ and manipulation of key metabolic enzymes such as fructose-1, 6-bisphosphatase (FBPase), and Sedoheptulose-1, 7-bisphosphatase (SBPase) (Edmeades et al., 1999; Sahrawy et al., 2004; Sticklen, 2006; Hay, 2012; Rosenthal et al., 2011).

Selection of improved cultivars under well-watered conditions and mild water stress at flowering reportedly enhanced biomass partitioning and resulted in higher harvest index in tropical maize populations (Edmeades et al., 1999). Similarly, the increase in atmospheric $\mathrm{CO}_{2}$ has also been reported to increase biomass production in the plant. However, it should be noted that such an increase might not correlate with high net assimilation. Other factors such as water, nutrients, oxygen, and plant respiration need to be regulated for high biomass accumulation (Sticklen, 2006). The manipulation of key metabolic enzymes such as FBPase and SBPase can also improve biomass accumulation. When pea FBPase was downregulated in transgenic Arabidopsis, sucrose production increased suggesting that the production of high sugar may convert to greater biomass in the plant (Sticklen, 2006; Sahrawy et al., 
2004). This hypothesis was tested upon inoculation of maize plants with the bacterium Azospirilium brasilense containing higher levels of trehalose (Rodríguez-Salazar et al., 2009). It was reported that such inoculation conferred drought tolerance and a marked increase in leaf and root biomass of the plant (RodríguezSalazar et al., 2009). Similarly, when SBPase was overexpressed, the yield of tobacco and soybean yield improved in the field (Rosenthal et al., 2011; Hay, 2012). Since SBPase from maize was reported to be like FBPase, it could be speculated that overexpression of both enzymes in maize would potentially improve yield (Michelet et al., 2013).

\section{Sorghum as a biomass plant}

Sorghum like maize is a $\mathrm{C}_{4}$ plant but unlike maize has a higher photosynthetic efficiency. The stalk of some varieties, for instance, sweet sorghum, consists of mostly sucrose; thus, has nearly $60 \%$ of sugar in its dry matter (Antonopoulou et al., 2008). The overall content of fermentable sugars is therefore considered high in sorghum particularly in sweet sorghum varieties (Calviño and Messing, 2012). It also has the potential to produce not just sugars, but starch and cellulose in higher amount than any other species (Rooney et al., 2007). Industrially, the best-known energy products from sorghum are ethanol, methane and more recently hydrogen (Antonopoulou et al., 2008). Sorghum grown for bioenergy production is regarded as a superior choice over maize because it has high water use efficiency and drought tolerance, gives higher yield and is easier to manipulate genetically using genetic and traditional methods (Rooney et al., 2007). Some strategies that have been shown or suggested to improve either drought tolerance and/or biomass accumulation in sorghum include high photosynthetic efficiency, increase in atmospheric $\mathrm{CO}_{2}$, stay green trait, high stem sugar and manipulation of small RNAs (Borrell et al., 2000; Antonopoulou et al., 2008, Calviño and Messing, 2012, Ottman et al., 2001).

Sorghum is known to have high photosynthetic efficiency and this is maintained for a long period during drought relative to other $\mathrm{C}_{4}$ species like maize (Antonopoulou et al., 2008; Ogbaga et al., 2014). High photosynthetic efficiency can translate to higher biomass production, which would be ideal for biofuel production. In terms of the effect atmospheric $\mathrm{CO}_{2}$, free-air $\mathrm{CO}_{2}$ enrichment (FACE) when applied to sorghum plants grown in the field has been found to improve biomass accumulation in dry plots (Ottman et al., 2001). This finding suggests that if biofuel companies invest in increasing $\mathrm{CO}_{2}$ concentration in plots used for sorghum planting, yield could increase. However, this approach is not economical and might not be easy for a company with limited funds. Another strategy involves the use of stay green sorghum hybrids. Such hybrids reportedly produced significantly more grain yield than senescent lines under drought (Borrell et al., 2000). Stay green sorghum lines have been reported to exhibit improved grain yield and mass relative to senescent lines. Therefore, biofuel companies can aim to target sorghum stay green lines in order to improve biomass production (Borrell et al., 2014). Finally, high stem sugar is generally observed in sweet sorghum compared with grain sorghum (Calviño and Messing, 2012). In addition, RNA, miR169, of the transcriptome from grain and sweet sorghum stems was characterized by Calvino and colleagues (Calviño et al., 2011).

They reported that miR169 expression played a role in drought response and correlated with sugar content. Thus, a greater expression of this small RNA could also have a role in biomass accumulation (Calviño et al., 2011; Calviño and Messing, 2012). Similarly, it has been reported that many cell wall-related or lignin genes can also influence biomass accumulation and degradability of sorghum (Oliver et al., 2005). A comparative study of wild-type sorghum lignin content relative to bmr mutants showed that mutants had lower lignin content relative to wild-type (Oliver et al., 2005). In addition, the proportion of specific components of improved starch contents such as amylopectin and amylose can be genetically modified in sorghum (Sarath et al., 2008). Sorghum with lower lignin and improved starch contents can represent alternative biofuel source (Sarath et al., 2008). In addition, some efforts have also been made earlier to develop photoperiod-sensitive sorghum hybrids, which have a longer vegetative growth period to produce higher biomass (Rooney and Aydin, 1999). With the specific genetic combinations of photoperiod-insensitive parental lines, hybrids have been created with high yield of up to $80 \mathrm{mg} \mathrm{ha}^{-1}(65 \%$ moisture) in a single harvest (McCollum et al., 2005). These genotypes were also higher in drought tolerance and/or drought avoidance in rainfed environments.

Novel mechanisms used by Sorghum for improved drought tolerance: It is established that Sorghum maintains photosynthesis longer than maize and is accompanied by greater PSIl photochemistry (Ogbaga et al., 2014). Also, provided moisture is sufficient, it maintains stable water relations irrespective of temperature (Machado and Paulsen, 2001). In order to elucidate the traits that contribute to improved drought tolerance, two varieties of sorghum, Samsorg 17 (more tolerant) and Samsorg 40 (less tolerant) from the Institute of Agricultural Research, Zaria, Nigeria were recently studied by Ogbaga and co-workers (Ogbaga et al., 2014; Ogbaga et al., 2016).

The traits that enabled the more tolerant Samsorg 17 to tolerate drought longer were presented. These traits includemaintenance of Rubisco large subunit (RbcL), high constitutive leaf sugar accumulation, sugar alcohol accumulation, low levels of glycine betaine and proline production, high expression of stress and late embryogenesis abundant (LEA) proteins (Ogbaga et al., 2014; Ogbaga et al., 2016). Maintenance of RbcL in the more drought tolerant Samsorg 17 can be an indication of a more efficient $\mathrm{CO}_{2}$ fixation during drought relative to Samsorg 40. High constitutive leaf sugar accumulation seen in Samsorg 17 offered protection during drought by lowering leaf, shoot and root water potential which enabled a more effective water uptake and longer leaf function in the plants (Fig. 1). Specific reengineering of photosynthetic apparatus occurred in less tolerant Samsorg 40. Plants of Samsorg 40 lost proteins with the nitrogen released 
used for amino acid production and maintenance of ATP (Fig. 1) Maintenance of photosynthetic proteins and high constitutive sugars were seen in Samsorg 17 in contrast to Samsorg 40 where loss of proteins and sugar accumulation occurred (Fig. 1). In addition, in Samsorg 40 plants, glycine betaine and proline accumulated in high proportions with increasing drought. The absence of such specific reengineering in Samsorg 17 means that the plant probably had a more active ATP resulting from a higher change in thylakoid $\mathrm{pH}$ gradient, which led to higher NPQ generation (Ogbaga et al., 2014).

Biochemical analyses of tissues of Samsorg 17 and Samsorg 40 in terms of metabolism and selected proteins revealed that greater accumulation of sugars, sugar alcohols, lipids, organic acids, heat shock proteins, and dehydrins are vital for drought tolerance. The tolerant Samsorg 17 accumulated these metabolites with greater protein induction or expression while less tolerant Samsorg 40 relied on accumulation of amino acid. These are two different approaches of drought tolerance with that of Samsorg 17 being a better approach (Ogbaga and Stępień, 2015). These traits represent a situation where Samsorg 17 plants receive early signals and become equipped as quickly as possible to deal with drought while Samsorg 40 plants do not receive such signals and have to respond to the condition. Samsorg 17 may have a memory of activating and possibly remembering strategies that can enhance survival under drought (Niu et al., 2014). In addition, other reports have identified further traits that protect sorghum against drought and a combination of drought and heat stress. These traits include specific transcription factors- MYB78 and ATAF1, polyamine metabolic biosynthetic pathway and the genes $\mathrm{SbDHN} 1$ and SbCA involved in dehydrin and carbonic anhydrase biosynthetic pathways, respectively (Johnson et al., 2014, Fracasso et al., 2016). Another gene SbNADP-ME is crucial in maintaining drought tolerance and encodes for NADP- malic enzyme expression (Fracasso et al., 2016).

Limitations of using Maize and Sorghum for biomass purposes: The use of both Maize and Sorghum for biomass purposes is promising and environmentally friendly. However, their use have certain limitations which include: the cost of fuel from plants, competition of plants grown for food and biomass/bioenergy and availability of plants. It is argued that bioethanol is more expensive than petrol (Nguyen and Prince, 1996). This is particularly due to the high cost of processing biomass into liquid fuel rather than cost or availability of feedstock (Lynd et al., 2008). Nevertheless, mixed cropping involving a variety of biomass crops can be helpful in optimizing production (Nguyen et al., 1996). In addition, breeding of traits from more drought tolerant varieties, in this case, sorghum into less tolerant maize is

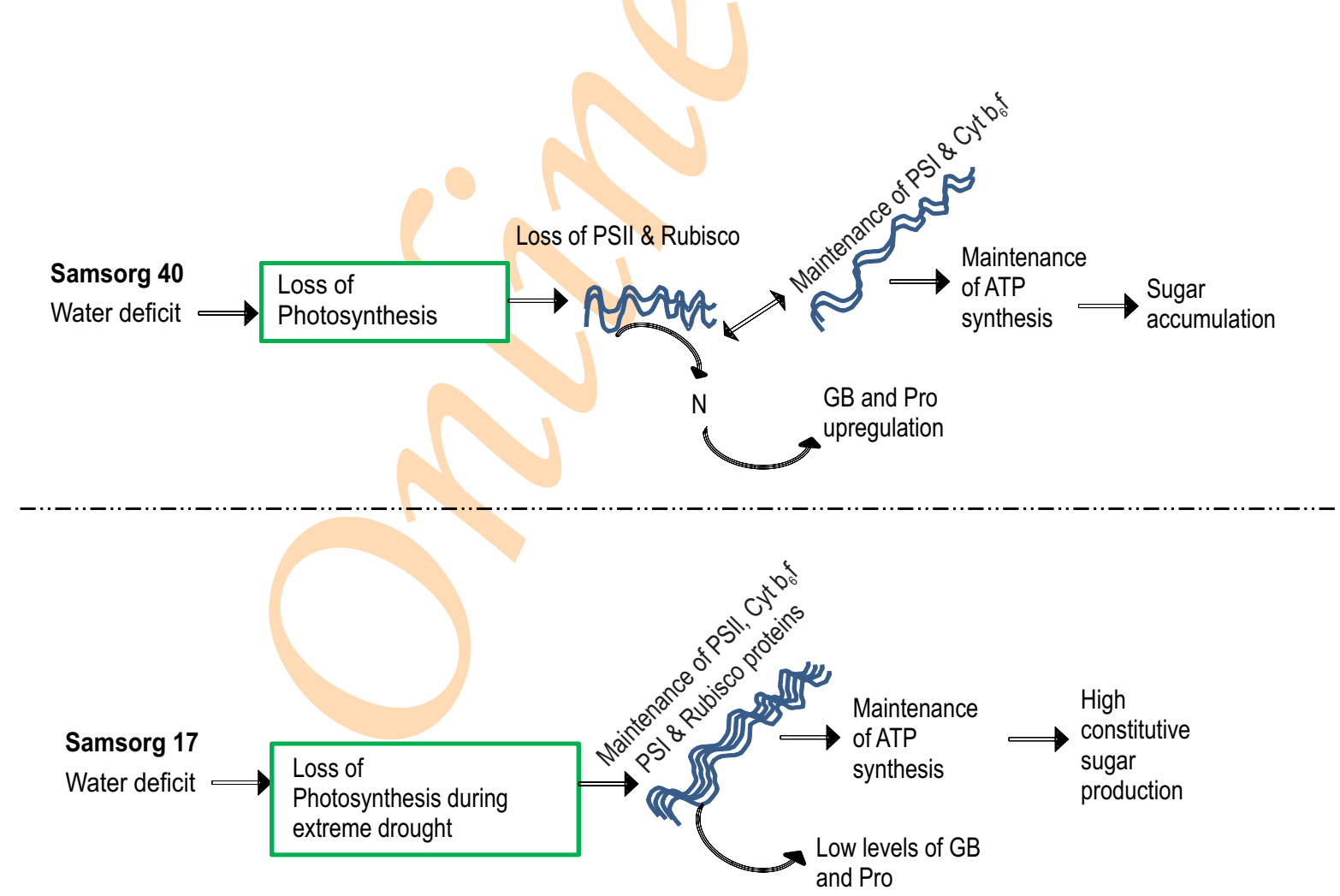

Fig. 1: Overview of the novel drought tolerance mechanisms in two sorghum cultivars- Samsorg 17 (more drought tolerant) and Samsorg 40 (less drought tolerant). 
expected to further increase the plant's productivity. In terms of competition of plants for food and biomass/bioenergy, there is a need for the production and growth of both crops, specifically developed for biomass and bioenergy production. Such crops can be grown in regions currently unsuitable for food crops, thus, minimizing the competition between food and biomass /bioenergy (Rooney et al., 2007). Similarly, competition with other renewable sources such as wind, solar and wave power falls under this limitation (McKendry, 2002b). The third limitation is that the plants need to be harvested in large quantity regardless of conversion technology used to provide adequate biomass feedstock. Given the current scenario, the pressing question is will harvesting huge amount of plants not cause erosion reduction in food production and depletion of soil carbon and nutrients? (Rooney et al., 2007).

Optimization of biomass conversion to sugars: Biotechnological industries can focus on optimizing biomass conversion to sugars in order to boost ethanol and energy production. However, this requires a lot of innovation, investment, and manpower (Lynd et al., 2008). The use of improved corn and sorghum crop varieties can be considered for this purpose. These crops can be genetically manipulated to produce more cellulose hydrolyzing enzymes capable of breaking down cellulose in favor of sugar production (Lynd et al., 2008). Prior to sugar production, the crops would go through the normal biomass conversion cycle that entails feedstock harvest and storage, thermochemical, physical or biological pre-treatment and enzymatic hydrolysis (Himmel et al., 2007). The use of thermochemical pre-treatment for hydrolysis is fast in breaking down the polymer chains (cellulose, hemicellulose and lignin) relative to physical and biological pretreatments. However, the limitation to its use for sugar production is the high cost of processing and formation of toxic substances (Kumar et al., 2009). Physical pre-treatment involves mechanical power i.e., grinding or milling to reduce cellulose crystallinity with a major disadvantage being the consumption of high energy for the process. In contrast, in biological pretreatment, fungi, bacteria, and protozoans produce cellulase which catalyzes the hydrolysis of cellulose. Biological pretreatment is time-consuming but uses less energy. During pretreatment, the polymer chains contained by the plants would be solubilized and made enzymatically digestible and accessible to saccharifying enzymes (Himmel et al., 2007). This is usually followed by the enzymatic breakdown of cell wall made up of lignin.

Three major saccharifying enzymes involved in this process are celluloses, hemicelluloses and accessory enzymes such as phenolic acid esterase and enzymes capable of degrading and modifying lignin (Himmel et al., 2007). For largescale production of biofuel, it is pertinent to consider sustainable feedstock production. This would undoubtedly involve production of the two crops in large amount with the crops processed using the best pre-treatment option from limited available land.

Summary: In conclusion, it is believed that the traits summarised in this article have provided new insights into both known and novel mechanisms that enhance drought tolerance and/or biomass accumulation in sorghum. These traits when genetically manipulated and transferred into maize may improve the use of limited agricultural land and lead to sustainable biofuel production. Particularly it has been shown that improved breeding and manipulation of photosynthetic enzymes are crucial for improving drought tolerance and biomass. It was also shown in the article that NPQ generation, high constitutive leaf sugar accumulation, sugar alcohol accumulation, maintenance of specific photosynthetic proteins, greater induction of droughtinduced proteins, low levels of glycine betaine and proline and accumulation of various metabolites in sorghum are important for survival during drought. In addition, specific transcription factorsMYB78 and ATAF1, polyamine metabolic biosynthetic pathway and genetic contributions such as genes SbDHN1, SbCA, SbNADP-ME involved in dehydrin, carbonic anhydrase and NADP-malic enzyme pathways are crucial for the maintenance of drought tolerance. As some of the traits discussed were obtained from plants mostly grown in pots and/or growth rooms under laboratory conditions, it is proposed that plants should be tested in greenhouse and in field to confirm reproducibility. Also, during breeding, selection of specific traits highlighted could be a good strategy to improve crop production during drought and potentially enhance biomass accumulation in a closely related species like maize. Currently, the use of both plants for largescale commercial purposes has not been achieved due to the limitations mentioned in the review. Thus, future research should address the limitations to promote the commercialization of both plants for biomass/bioenergy purposes.

Future Research: Laboratory experiments use artificial conditions to study plants' responses to stresses. Results from such experiments are usually far from what could be obtained when similar experiments are performed in the field. Thus, field experiments in natural plant growth conditions would be useful to test the reproducibility of some of the laboratory-generated traits summarised in this review. In addition, attempts should be made to ensure that the best crop varieties are grown in the fields to produce maximum biomass and that harvests are optimized through pre-treatment to promote the commercialization of biofuel production from the plants (Ogbaga et al., 2018).

In order to uncouple further mechanisms that can improve drought tolerance and biomass accumulation, there is a need to invest in biotechnology and more synergistic studies (Alonge et al., 2017). Genetic studies described in the review suggest that genetic engineering is undoubtedly one way to enhance biomass production of plants. Continued increase in knowledge of molecular pathways that modulate phytochemical composition and genetic variations is needed for better understanding of pathways capable of controlling biomass production for biofuel production (Calviño and Messing, 2012). Crop varieties with interesting traits can be studied further using a combination of approaches-systems biology, imaging and computational tools, phenomics (a high throughput phenotypic screening), genomics, transcriptomics, proteomics and 
metabolomics (Lynd et al., 2008; Driever et al., 2013; Athar et al., 2016; Ogbaga, 2017; Ogbaga et al., 2017a). Finally, experimental designs and methods can be enhanced with modeling studies (Niu et al., 2014). These can be used to improve our understanding of the regulatory networks of drought on plants metabolism.

\section{References}

Antonopoulou, G., H.N. Gavala, I.V. Skiadas, K. Angelopoulos and G. Lyberatos: Biofuels generation from sweet sorghum: Fermentative hydrogen production and anaerobic digestion of the remaining biomass. Bioresour. Technol., 99, 110-119 (2008).

Alonge, O.O., C.C. Ogbaga and F.M. Mairami: Phytotoxic analysis of the impact of transmission oil contaminated soil on germination and growth of Oat (Avena sativa) seedlings under different soil moisture conditions. Global J. Pure Appl. Sci., 23, 249-253 (2017).

Athar, H.R., S. Ambreen, M. Javed, M. Hina, S. Rasul, Z.U. Zafar, H. Manzoor, C.C. Ogbaga, M. Afzal, F. Al-Qurainy and M. Ashraf: Influence of sub-lethal crude oil concentration on growth, water relations and photosynthetic capacity of maize (Zea mays L.) plants. Environ. Sci.Pollut. Res. Int., 23, 18320-18331 (2016).

Asada, K.: Production and scavenging of reactive oxygen species in chloroplasts and their functions. Plant Physiol.,141, 391-396 (2006)

Blum, A.: Plant Breeding For Stress Environments. CRC Press (1988)

Blum, A.: Plant Breeding For Water-Limited Environments. Springer New York (2011).

Borrell, A.K., G.L. Hammer and R.G. Henzell: Does maintaining green leaf area in sorghum improve yield under drought? li. Dry matter production and yield. Crop Sci., 40, 1037-1048 (2000)

Borrell, A.K., J.E. Mullet, B. George-Jaeggli, E.J. Van Oosterom, G.L. Hammer, P.E. Klein and D.R. Jordan: Drought adaptation of staygreen sorghum is associated with canopy development, lea anatomy, root growth, and water uptake. J. Exp. Bot., 65, 62516263 (2014).

Calviño, M., R. Bruggmann and J. Messing: Characterization of the small RNA component of the transcriptome from grain and sweet sorghum stems. Bmc Genomics, 12, 1(2011).

Calviño, M. and J. Messing: Sweet sorghum as a model system for bioenergy crops. Curr. Opin. Biotechnol., 23, 323-329 (2012).

Carmo-Silva, E., M. Gore, P. Andrade-Sanchez, A. French, D. Hunsaker and M. Salvucci: Decreased $\mathrm{CO}_{2}$ availability and inactivation of rubisco limit photosynthesis in cotton plants under heat and drought stress in the field. Environ. Exp. Bot., 83, 1-11 (2012).

Carpita, N.C. and M.C. Mccann: Maize and sorghum: genetic resources for bioenergy grasses. Trends Plant Sci., 13, 415-420 (2008).

Chaves, M., J. Maroco and J. Pereira: Understanding plant responses to drought- from genes to the whole plant. Funct. Plant Biol., 30, 239 $264(2003)$

Chaves, M.M., J. Flexas and C. Pinheiro: Photosynthesis under drought and salt stress: Regulation mechanisms from whole plant to cell. Ann. Bot., 103, 551-560 (2009).

Chen, J., W. Xu, J. Velten, Z. Xin and J. Stout: Characterization of maize inbred lines for drought and heat tolerance. J. Soil Water Conser., 67, 354-364 (2012).

Chen, Z., T.A. Cuin, M. Zhou, A. Twomey, B.P. Naidu and S. Shabala: Compatible solute accumulation and stress-mitigating effects in barley genotypes contrasting in their salt tolerance. J. Exp. Bot., 58, 4245-4255 (2007).

Driever, S.M. and J. Kromdijk: Will $\mathrm{C}_{3}$ crops enhanced with the $\mathrm{C}_{4} \mathrm{CO}_{2}$ concentrating mechanism live up to their full potential (yield)? $\mathrm{J}$.
Exp. Bot., 64, 3925-3935 (2013).

Edmeades, G., S. Chapman and H. Lafitte: Selection improves drought tolerance in tropical maize populations: i. Gains in biomass, grain yield and harvest index. Crop Sci., 39, 1306-1315 (1999).

Flexas, J. and H. Medrano: Drought-inhibition of photosynthesis in $\mathrm{C}_{3}$ plants: Stomatal and non-stomatal limitations revisited. Annals Bot., 89, 183-189 (2002).

Fracasso, A., L. Trindade and S. Amaducci: Drought tolerance strategies highlighted by two sorghum bicolor races in a dry-down experiment. J. Plant Physiol., 190, 1-14 (2016).

Ghannoum, O.: $\mathrm{C}_{4}$ photosynthesis and water stress. Annals Bot.,103, 635-644 (2009).

Hay, W.: Engineering cyanobacterial genes into Glycine max (soybean) leads to increased photosynthesis and productivity. The University of Illinois, Urbana-Champaign (2012).

Himmel, M.E., S.Y. Ding, D.K. Johnson, W.S. Adney, M.R. Nimlos, J.W. Brady and T.D. Foust: Biomass recalcitrance: Engineering plants and enzymes for biofuels production. Science, 315, 804-807 (2007)

IPCC.: Working group i contribution to the IPCC fifth assessment report climate change 2013: the physical science basis. Final Draft Underlying Scientific- Technical Assessment. Stockholm (2013).

Johnson, S.M., F.L. Lim, A. Finkler, H. Fromm, A.R. Slabas and M.R. Knight: Transcriptomic analysis of sorghum bicolor responding to combined heat and drought stress. Bmc Genomics, 15, 456 (2014)

Kumar, P., D.M. Barrett, M.J. Delwiche and P. Stroeve: Methods for pretreatment of lignocellulosic biomass for efficient hydrolysis and biofuel production. Ind. Eng. Chem. Res., 48, 3713-3729 (2009).

Lawrence, C.J. and V. Walbot: Translational genomics for bioenergy production from fuelstock grasses: Maize as the model species. Plant Cell, 19, 2091-2094 (2007).

Lynd, L.R., M.S. Laser, D. Bransby, B.E. Dale, B. Davison, R. Hamilton M. Himmel, M. Keller, J.D. Mcmillan and J. Sheehan: How biotech can transform biofuels. Nature Biotechnol., 26, 169-172 (2008).

Machado, S. and G.M. Paulsen: Combined effects of drought and high temperature on water relations of wheat and sorghum. Plant Soil, 233, 179-187 (2001)

Mccollum, T., K. McCuistion and B. Bean: Brown midrib and photoperiod sensitive forage sorghums. Proceedings of the 2005 Plains Nutrition Council Spring Conference, pp. 05-20 (2005).

Mckendry, P.: Energy production from biomass (Part 1): Overview of biomass. Bioresour. Technol., 83, 37-46 (2002a).

Mckendry, P.: Energy production from biomass (Part 2): Conversion technologies. Bioresour. Technol., 83, 47-54 (2002b)

Medrano, H., J.M. Escalona, J. Bota, J. Gulias and J. Flexas: Regulation of photosynthesis of $\mathrm{C}_{3}$ plants in response to progressive drought: Stomatal conductance as a reference parameter. Ann. Bot., 89, 895-905 (2002)

Michelet, L., M. Zaffagnini, S. Morisse, F. Sparla, M.E. Pérez-Pérez, F. Francia, A. Danon, C.H. Marchand, S. Fermani and P. Trost: Redox regulation of the Calvin-Benson Cycle: Something old, something new. Thiol-Based Redox Homeost. Sign., 4 (2013). doi: 10.3389/fpls.2013.00470

Miyake, C., Y. Shinzaki, M. Miyata and K.I. Tomizawa: Enhancement of cyclic electron flow around psi at high light and its contribution to the induction of non-photochemical quenching of chl fluorescence in intact leaves of tobacco plants. Plant Cell Physiol., 45, 14261433 (2004)

Nguyen, M. and R. Prince: A simple rule for bioenergy conversion plant size optimization: Bioethanol from sugar cane and sweet sorghum. Biomass Bioenerg.,10, 361-365 (1996). 
Niu, S., Y. Luo, D. Li, S. Cao, J. Xia, J. Li and M.D. Smith: Plant growth and mortality under climatic extremes: An overview. Environ. Exp. Bot., 98, 13-19 (2014).

Ogbaga, C.C.: Effects of regionally applied heating on the respiration of wild-type and transgenic soybean (Glycine max) plants grown under ambient and elevated $\mathrm{CO}_{2}$ environments. Afr. J. Biotechnol., $16,65-86(2017)$

Ogbaga, C.C.: Climate change- the West African experience. Science (eLetter), 359, 997-998 (2018).

Ogbaga, C.C., M.A. Miller and G.N. Johnson: Fourier transform infrared spectroscopic analysis of maize (Zea mays) subjected to progressive drought reveals involvement of lipids, amides and carbohydrates. Afr. J. Biotechnol, 16, 1061-1066 (2017a).

Ogbaga, C.C., F.A. Nuruddeen, O.O. Alonge and O.F. Nwagbara: Phytochemical, elemental and proximate analyses of stored, sun-dried and shade-dried baobab (Adansonia digitata) leaves. In $13^{\text {th }}$ International Conference On Electronics, Computer and Computation (ICECCO), IEEE, 1-5 (2017b).

Ogbaga, C.C. and P. Stępień: Recovery after drought in two sorghum cultivars with differing drought tolerance. Zeszyty Naukowe Uniwersytetu Przyrodniczego We Wrocawiu: Rolnictwo (2015).

Ogbaga, C.C., P. Stepien, H.U.R. Athar and M. Ashraf: Engineering Rubisco activase from thermophilic cyanobacteria into hightemperature sensitive plants. Crit. Rev. Biotechnol., 38, 559-572 (2018).

Ogbaga, C.C., P. Stepien, B.C. Dyson, N.J. Rattray, D.I. Ellis, R. Goodacre and G. N. Johnson: Biochemical analyses of sorghum varieties reveal differential responses to drought. Plos One, 11, E0154423 (2016).

Ogbaga, C.C., P. Stepien and G.N. Johnson: Sorghum (Sorghum bicolor) varieties adopt strongly contrasting strategies in response to drought. Physiol. Plant, 152, 389-401 (2014).

Oliver, A., J. Pedersen, R. Grant, T. Klopfenstein and H. Jose: Comparative effects of the sorghum bmr- 6 and bmr-12 genes: ii. Grain yield, stover yield, and stover quality in grain sorghum. Crop Sci., 45, 2240 (2005).

Ottman, M., B. Kimball, P. Pinter, G. Wall, R. Vanderlip, S. Leavitt, R. Lamorte, A. Matthias and T. Brooks: Elevated $\mathrm{CO}_{2}$ increases sorghum biomass under drought conditions. New Phytologist, 150 261-273 (2001).

Paterson, A.H., J.E. Bowers, R. Bruggmann, I. Dubchak, J. Grimwood H. Gundlach, G. Haberer, U. Hellsten, T. Mitros and A. Poliakov: The Sorghum bicolor genome and the diversification of grasses. Nature, 457, 551-556 (2009a)

Paterson, A.H., J.E. Bowers, R. Bruggmann, I. Dubchak, J. Grimwood, H. Gundlach, G. Haberer, U. Hellsten, T. Mitros, A. Poliakov, J. Schmutz, M. Spannagl, H. Tang, X. Wang, T. Wicker, A.K. Bharti, J. Chapman, F.A. Feltus, U. Gowik, I.V. Grigoriev, E. Lyons, C.A Maher, M. Martis, A. Narechania, R.P. Otillar, B.W. Penning, A.A. Salamov, Y. Wang, L. Zhang, N.C. Carpita, M. Freeling, A.R. Gingle, C.T. Hash, B. Keller, P. Klein, S. Kresovich, M.C. Mccann, R. Ming, D.G. Peterson, R. Mehboob Ur, D. Ware, P. Westhoff, K.F.X. Mayer, J. Messing and D.S. Rokhsar: The Sorghum bicolor genome and the diversification of grasses. Nature, 457, 551-556 (2009b).

Pennisi, E.: Corn genomics pops wide open. Science, 319, 1333-1333 (2008).
Poorter, H. and C. Remkes: Leaf area ratio and net assimilation rate of 24 wild species differing in relative growth rate. Oecologia, 83, 553559 (1990).

Rodríguez-Salazar, J., R. Suárez, J. Caballero-Mellado and G. Iturriaga: Trehalose accumulation in Azospirillum brasilense improves drought tolerance and biomass in maize plants. Fems Microbiol. Let., 296, 52-59 (2009).

Rooney, W.L. and S. Aydin: Genetic control of a photoperiod-sensitive response in Sorghum bicolor (I.) Moench. Crop Sci., 39, 397-400 (1999).

Rooney, W.L., J. Blumenthal, B. Bean and J.E. Mullet: Designing sorghum as a dedicated bioenergy feedstock. Biofuel. Bioprod. Bior., 1, 147-157 (2007).

Rosenthal, D.M., A.M. Locke, M. Khozaei, C.A. Raines, S.P. Long and D.R. Ort: Over-expressing the $C_{3}$ photosynthesis cycle enzyme sedoheptulose-1-7 bisphosphatase improves photosynthetic carbon gain and yield under fully open-air $\mathrm{CO}_{2}$ fumigation (face). BMC Plant Biol., 11, 123 (2011)

Sahrawy, M., C. Ávila, A. Chueca, F.M. Cánovas and López-Gorgé: Increased sucrose level and altered nitrogen metabolism in Arabidopsis thaliana transgenic plants expressing antisense chloroplastic fructose-1, 6-bisphosphatase. J. Exp. Bot., 55, 24952503 (2004)

Sarath, G., R.B. Mitchell, S.E. Sattler, D. Funnell, J.F. Pedersen, R.A. Graybosch and K.P. Vogel: Opportunities and roadblocks in utilizing forages and small grains for liquid fuels. J. Ind. Microbiol. Biotechnol., 35, 343-354 (2008)

Sticklen, M.: Plant genetic engineering to improve biomass characteristics for biofuels. Curr. Opin. Biotechnol., 17, 315-319 (2006).

Takabayashi, A., M. Kishine, K. Asada, T. Endo and F. Sato: Differential use of two cyclic electron flows around photosystem I for driving $\mathrm{CO}_{2}$ concentration mechanism in $\mathrm{C}_{4}$ photosynthesis. Proc. Natl. Acad. Sci. USA., 102, 16898-16903 (2005).

Turyagyenda, L., E.B. Kizito, M. Ferguson, Y. Baguma, M. Agaba, J.J.W. Harvey and D.S.O. Osiru: Physiological and molecular characterization of drought responses and identification of candidate tolerance genes in cassava. Aob Plants, 5, 1-17(2013).

Yamori, W., K. Hikosaka and D. Way: Temperature response of photosynthesis in $\mathrm{C}_{3}, \mathrm{C}_{4}$, and CAM plants: Temperature acclimation and temperature adaptation. Photosynth. Res., 119, 101-117 (2014).

$\mathrm{Yu}$, J. and E.S. Buckler: Genetic association mapping and genome organization of maize. Curr. Opin. Biotechnol., 17, 155-160 (2006).

Yu, J., J.B. Holland, M.D. Mcmullen and E.S. Buckler: Genetic design and statistical power of nested association mapping in maize. Genetics, 178, 539-551. (2008)

Zafar, Z.U., H. Manzoor, S. Rasul, S. Noreen, Q. Ali, M. Iqbal, M. Javed, H.S. Gul, Z. Ahmad, F. Shahzad, C.C. Ogbaga, H.R. Athar and M. Ashraf: Strategies to improve crop salt and drought tolerance: Success and limitations. Agrobios (India), 11, 265-298 (2017).

Zegada-Lizarazu, W. and A. Monti: Photosynthetic response of sweet sorghum to drought and re-watering at different growth stages. Phys. Plant., 149, 56-66. (2013).

Zhu, X.G., S.P. Long and D.R. Ort: What is the maximum efficiency with which photosynthesis can convert solar energy into biomass? Curr. Opin. Biotechnol., 19, 153-159 (2008). 